\title{
Serum biomarker analysis of collagen disease patients with acute-onset diffuse interstitial lung disease
}

\author{
Shomi Oka ${ }^{1}$, Hiroshi Furukawa ${ }^{1 *}$, Kota Shimada ${ }^{2,3}$, Hiromi Hayakawa ${ }^{1}$, Naoshi Fukui ${ }^{1}$, Naoyuki Tsuchiya ${ }^{4}$ \\ and Shigeto Tohma'
}

\begin{abstract}
Background: Interstitial lung disease (ILD) is frequently associated with collagen diseases. The prognosis of acute-onset diffuse ILD (AoDILD) occurring in collagen disease patients is very poor. Here, we investigated serum biomarker profiles of AoDILD to find markers predicting outcome in patients with collagen diseases.

Methods: A solid-phase antibody array was used for screening 274 biomarkers in pooled sera from collagen disease patients in the AoDILD state and in the stable state. Biomarkers in individual sera were detected without pooling by bead-based immunoassay.

Results: The serum levels of matrix metalloproteinase (MMP)-1, tissue inhibitor of metalloproteinase (TIMP)-1, osteopontin, interleukin (IL)-2 receptor a (IL-2Ra), and IL-1 receptor antagonist were significantly increased in AoDILD, but TIMP-2, MMP-3, and eotaxin 2 levels were decreased. The MMP-3 to MMP-1 ratio was reduced in AoDILD state. This tendency was also observed in RA patients with AoDILD. Moreover, serum IL-6 level was significantly increased in the AoDILD state in patients with acute exacerbation of ILD (AE-ILD). Serum TIMP-1 and IL-2Ra levels were significantly increased in the AoDILD state in patients with drug-induced ILD (DI-ILD), whereas TIMP-2, MMP-3, and eotaxin 2 levels were decreased. The MMP-3 to MMP-1 ratio was reduced in AoDILD state in patients with DI-ILD. The serum TIMP-3, MMP-9, osteopontin, IL-2Ra, MMP-1, and MMP-8 levels were significantly increased in the AoDILD state in patients who subsequently died, whereas TIMP-2 and MMP-3 levels were decreased in those who survived. The MMP-3 to MMP-1 ratio was reduced in AoDILD state in patients who died, but not in those who survived.
\end{abstract}

Conclusions: Serum biomarker profiles could represent prognosis markers for AoDILD in collagen diseases.

Keywords: Collagen disease, Biomarker, Cytokine, Interstitial lung disease

\section{Background}

Interstitial lung disease (ILD) is characterized by interstitial inflammation of the lung and is frequently associated with collagen diseases, when it is designated collagen vascular disease-associated ILD (CVD-ILD). CVD-ILD is one of the major manifestations of collagen disease that influence the prognosis [1,2]. Acute-onset diffuse ILD (AoDILD) occurs in patients with collagen disease with

\footnotetext{
* Correspondence: h-furukawa@sagamihara-hosp.gr.jp

${ }^{1}$ Clinical Research Center for Allergy and Rheumatology, Sagamihara Hospital, National Hospital Organization, 18-1 Sakuradai, Minami-ku, Sagamihara,

Kanagawa 252-0392, Japan

Full list of author information is available at the end of the article
}

or without underlying CVD-ILD [3]. AoDILD includes acute exacerbation of ILD (AE-ILD), drug-induced ILD (DI-ILD), and Pneumocystis pneumonia. The prognosis of AoDILD is quite poor. AE-ILD is due to collagen diseases per se and characterized by pathological findings of diffuse alveolar damage overlapping with chronic fibrotic lung. DI-ILD occurs frequently in rheumatoid arthritis (RA) patients treated with methotrexate. Pneumocystis pneumonia is defined by the presence of $P$. jirovecii organisms in the respiratory tract. However, the classification of AoDILD is not established.

The roles of several cytokines, chemokines, matrix metalloproteinases (MMPs) and tissue inhibitors of

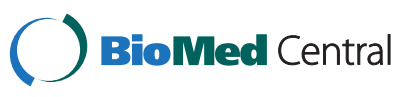

(c) Oka et al.; licensee BioMed Central Ltd. This is an Open Access article distributed under the terms of the Creative Commons Attribution License (http://creativecommons.org/licenses/by/2.0), which permits unrestricted use, distribution, and reproduction in any medium, provided the original work is properly cited. 
metalloproteinases (TIMPs) were reported in idiopathic pulmonary fibrosis (IPF) and in acute respiratory distress syndrome (ARDS) [4-6]. Few studies have focused on AoDILD in collagen diseases. Therefore, we investigated the serum biomarker profile of AoDILD in collagen diseases in order to shed light on pathogenesis and markers informative for disease severity or predicting outcome.

\section{Methods}

\section{Patients and sera}

Twenty-five patients with collagen diseases (mean age \pm standard deviation (SD): $65.9 \pm 10.8$ years; 11 men) were admitted to Sagamihara Hospital between 2001 and 2010, because of AoDILD requiring corticosteroid pulse therapy. AoDILD was defined as acute onset and progression within a month, the presence of clinical symptoms (fever, dry cough, or dyspnea), hypoxia, and computed tomography findings of ILD [3]. Patients with evidence of apparent bacterial infection or heart disease were excluded. These 25 collagen disease patients with AoDILD include 9 AE-ILD, 16 DI-ILD, and no Pneumocystis pneumonia. In this study, AoDILD was classified to AE-ILD, DI-ILD, and Pneumocystis pneumonia as following: Pneumocystis pneumonia was defined by the presence of $P$. jirovecii organisms detected by polymerase chain reaction for $P$. jirovecii or Grocott stain from bronchoalveolar lavage fluids or sputa of patients, DI-ILD was defined as AoDILD with treatment of DI-ILD causing drugs (disease-modifying anti-rheumatic drugs or immunosuppressants excluding corticosteroid) at onset after the exclusion of Pneumocystis pneumonia, AEILD was defined as AoDILD without treatment of DI-ILD causing drugs at onset, but with underlying CVD-ILD, after the exclusion of Pneumocystis pneumonia and DI-ILD. These 16 patients with DI-ILD were treated at onset with methotrexate $(\mathrm{n}=10)$, gold sodium thiomalate $(\mathrm{n}=1)$, tacrolimus $(\mathrm{n}=2)$, cyclophosphamide $(\mathrm{n}=1)$, or etanercept $(n=2)$. Sera were collected on admission, and in the stable state, at least three months before admission. They were classified according to the American College of Rheumatology criteria for RA [7], systemic sclerosis (SSc) [8], and Bohan's criteria for polymyositis/dermatomyositis (PM/ DM) [9]. Diagnoses of the patients included 20 RA, 2 SSc, and 3 PM/DM. These 25 collagen disease patients with AoDILD include 11 patients who died and 14 who survived, during the course of AoDILD. The major cause of death of these 11 patients would be respiratory failure due to AoDILD, though the complication of infection due to repetitive corticosteroid pulse therapy could not be completely excluded. This study was reviewed and approved by Sagamihara Hospital Research Ethics Committee. Written informed consent was obtained from all study participants except those already deceased before starting this study. The serum samples collected before this study were anonymized in a fashion preventing any link with the patients' identification and their analysis approved on that condition by Sagamihara Hospital Research Ethics Committee. This study was conducted in accordance with the principles expressed in the Declaration of Helsinki.

\section{Biomarker immunoassay}

RayBio human cytokine antibody array (RayBiotech, Norcross, GA) was used for detection of 274 biomarkers

Table 1 Biomarker levels in individual serum without pooling from collagen disease patients in the stable and AoDILD states

\begin{tabular}{|c|c|c|c|c|c|}
\hline Biomarker (pg/ml) & Stable & & AoDILD & & $P$ \\
\hline TIMP-1 & 207843 & (57972) & 285600 & (98476) & 0.015 \\
\hline TIMP-2 & 121481 & (22995) & 101922 & (18568) & 0.006 \\
\hline TIMP-3 & 15662 & (11925) & 15653 & (7974) & 0.196 \\
\hline TIMP-4 & 2908 & (941) & 2874 & (837) & 0.906 \\
\hline MMP-3 & 854165 & (668239) & 499442 & (312919) & 0.010 \\
\hline MMP-9 & 2615399 & (1577133) & 2837226 & (1619793) & 0.563 \\
\hline TGF- $\beta 1$ & 57391 & (12908) & 52821 & (16415) & 0.101 \\
\hline TGF- $\beta 2$ & 2475 & (889) & 2201 & (997) & 0.101 \\
\hline TGF- $\beta 3$ & 0 & (0) & 0 & (0) & 1.000 \\
\hline Leptin & 6424 & $(6663)$ & 6275 & (8249) & 0.670 \\
\hline Osteopontin & 14603 & (12657) & 30216 & (33636) & 0.012 \\
\hline Insulin & 633 & (475) & 589 & (330) & 0.961 \\
\hline EGF & 131 & (124) & 130 & (189) & 0.355 \\
\hline Eotaxin2 & 4497 & (3166) & 4223 & $(5065)$ & 0.018 \\
\hline Eotaxin3 & 44 & (71) & 37 & (52) & 0.625 \\
\hline IL-17 F & 125 & (340) & 168 & (519) & 0.761 \\
\hline IL-1a & 61 & (248) & 137 & $(607)$ & 1.000 \\
\hline IL-1RA & 156 & (330) & 401 & (490) & 0.049 \\
\hline IL-2 & 41 & (121) & 77 & (246) & 0.427 \\
\hline IL-2Ra & 3623 & (2134) & 7469 & $(6483)$ & 0.001 \\
\hline IL-6 & 103 & (234) & 363 & (794) & 0.035 \\
\hline Fas & 2237 & (9967) & 3450 & (13337) & 0.715 \\
\hline FasL & 68 & (63) & 74 & (74) & 0.763 \\
\hline TNFa & 841 & (1953) & 1052 & $(2676)$ & 0.821 \\
\hline MMP-1 & 69662 & (86194) & 75510 & (58379) & 0.016 \\
\hline MMP-12 & 4992 & (14919) & 7406 & (23641) & 0.500 \\
\hline MMP-7 & 5874 & (5153) & 7871 & $(11084)$ & 0.627 \\
\hline MMP-13 & 37860 & (74534) & 52019 & (111830) & 0.754 \\
\hline MMP-8 & 25817 & (17712) & 48700 & (54791) & 0.144 \\
\hline LIF & 57 & (150) & 121 & (353) & 0.441 \\
\hline MIF & 17352 & (34236) & 23178 & (29813) & 0.136 \\
\hline MMP-3/MMP-1 & 22.04 & (18.56) & 15.00 & (19.61) & 0.0208 \\
\hline
\end{tabular}

AoDILD: acute-onset diffuse interstitial lung disease. Average values of each group are shown. Standard deviations are shown in parenthesis. Differences were tested by Wilcoxon signed-rank test. 
in pooled sera of two states, AoDILD and stable, according to the manufacturer's protocol. The Bio-Plex suspension array system (Bio-rad, Hercules, CA) was used for detection of biomarkers in individual sera from patients in the two different states, without pooling. Fluorokine MAP multiplex kits (R\&D Systems, Minneapolis, MN) were used for detection of TIMP-1, TIMP-2, TIMP-3, and TIMP-4. Milliplex map kits (Millipore, Billerica, MA) were used for detection of transforming growth factor (TGF)- $\beta 1$, TGF- $\beta 2$, TGF- $\beta 3$, leptin, osteopontin, and insulin. Procarta cytokine plex kits (Affymetrix, Santa Clara, CA) were used for detection of MMP-3, MMP-9, epidermal growth factor (EGF), (IL)-17F, IL-1 $\alpha$, IL-1 receptor antagonist (IL-1RA), IL-2, IL-2 receptor $\alpha$ (IL-2R $\alpha$ ), IL-6, Fas, Fas ligand (FasL), tumor necrosis factor (TNF) $\alpha$, MMP-1, MMP-12, MMP-7, MMP-13, MMP-8, leukaemia inhibitory factor (LIF), and migration inhibitory factor (MIF).

\section{Statistical analysis}

Differences in patient characteristics were analyzed by Mann-Whitney $U$ test or Fisher's exact test using $2 \times 2$ contingency tables. Wilcoxon signed-rank test or Mann-Whitney U test was performed in the comparison of laboratory findings and biomarker assay results. It was defined statistical significance as $P<0.05$.

\section{Results}

Characteristics of collagen disease patients with AoDILD In $84 \%(n=21)$ of the patients with AoDILD, underlying CVD-ILD had been detected prior to the onset of AoDILD. Mortality of patients during the AoDILD state was $44 \%(\mathrm{n}=11)$. Lactate dehydrogenase, blood urea nitrogen, KL-6, and surfactant protein-D (SP-D) were more increased in AoDILD than in the stable state (Additional file 1: Table S1). Albumin was decreased in the AoDILD state compared to these patients in the stable state.

\section{Biomarker immunoassay}

Sera were pooled from 25 collagen disease patients in each state, i.e. stable and AoDILD. We assessed the presence of 274 biomarkers in these two pooled sera. Eighteen of them were found to be present at less than 0.67 times the level in the pooled sera at AoDILD compared to the stable state (Additional file 2: Table S2). Five biomarkers were present in AoDILD sera at levels more than 1.5 times the stable state. In addition to these 23 up-regulated or downregulated biomarkers, several biomarkers were included from the results of previous studies on IPF or ARDS for candidates of further analysis [4,6,10-18]. Thirty one biomarkers were selected based on the availability of bead-based immunoassay for more detailed analysis. Upregulated soluble TNF receptor II in this pooled assay
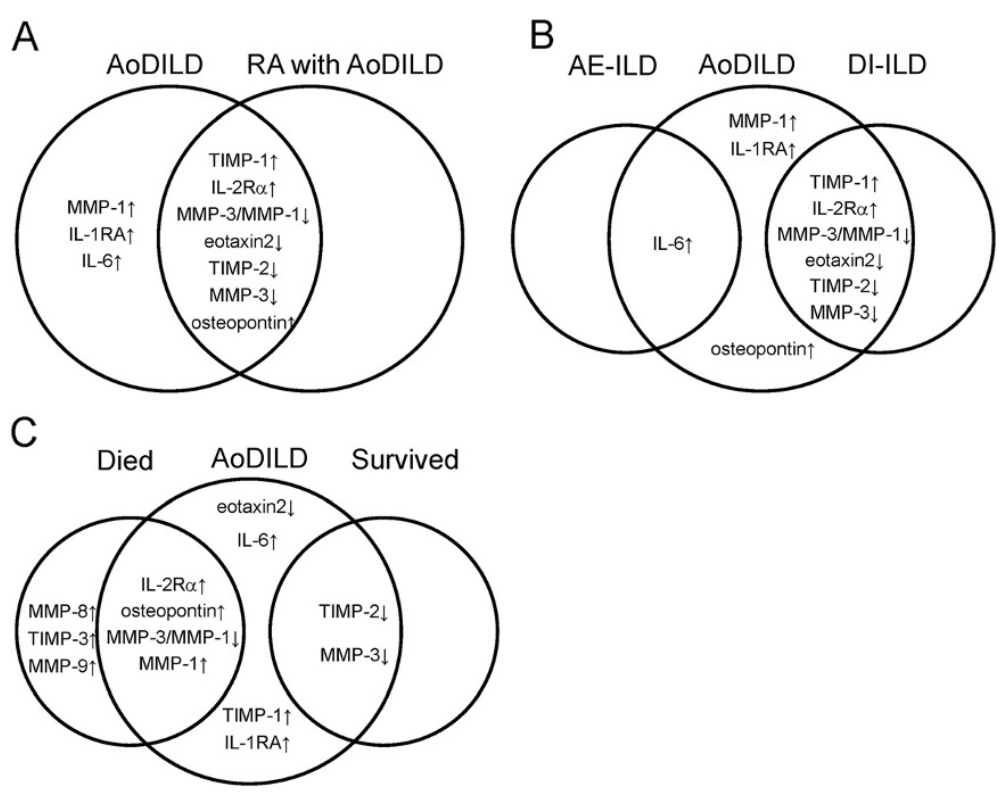

Figure 1 Biomarker profile of acute-onset diffuse interstitial lung disease (AoDILD). Increased and decreased biomarkers in AoDILD state of collagen disease and rheumatoid arthritis (RA) patients were indicated in A. Increased and decreased biomarkers in AoDILD state of acute exacerbation of ILD (AE-ILD) and drug-induced interstitial lung disease (DI-ILD) patients were indicated in B. Increased and decreased biomarkers in AoDILD state of patients who subsequently died and those who survived were indicated in $\mathbf{C}$. 
would be derived from the administered recombinant soluble TNF receptor II-Fc fusion protein, etanercept. Because administration of antibody or recombinant cytokine receptors skews the cytokine profile [19], sera from the 2 RA patients treated with etanercept were excluded from the following individual biomarker analysis. The serum biomarker levels of the 23 collagen disease patients in the stable state and at AoDILD without pooling are shown in Table 1 and Additional file 3: Figure S1. Serum TIMP-1, osteopontin, IL-1RA, IL$2 \mathrm{R} \alpha$, IL-6, and MMP-1 levels were significantly increased in the AoDILD state (Table 1, Figure 1A), whereas TIMP2, MMP-3, and eotaxin 2 levels were decreased. The ratio of MMP-3 to MMP-1 was reduced in the AoDILD state in these patients.
Serum biomarker profile of the RA patients with AoDILD We next explored biomarkers associated with AoDILD in the patients with RA. Characteristics of the RA patients $(n=18)$ are compared with that of collagen disease patients $(n=23)$ in Additional file 4: Table S3. The laboratory findings of the RA patients in the stable state and in the AoDILD state are shown in Table 2. KL-6, SP-D, and lactate dehydrogenase were increased in AoDILD of patients with RA. Albumin was decreased in AoDILD of patients with RA.

While the serum TIMP-1, osteopontin, and IL$2 \mathrm{R} \alpha$ levels were increased in patients with $\mathrm{RA}$ in the AoDILD state (Table 2, Figure 1A), TIMP-2, MMP-3, and eotaxin 2 were decreased. The ratio of MMP-3 to MMP-1 was also reduced in the AoDILD state in these

Table 2 Laboratory findings and serum biomarker levels of the RA patients in stable and AoDILD states

\begin{tabular}{|c|c|c|c|}
\hline & \multicolumn{2}{|c|}{ RA patients $(n=18)$} & \multirow[b]{2}{*}{$P$} \\
\hline & Stable & AoDILD & \\
\hline White Blood Cell count(X1000/ml) & $10.5(3.8)$ & $12.1(3.4)$ & 0.1578 \\
\hline Red Blood Cell count $\left(\times 10^{6} / \mathrm{ml}\right)$ & $4.2(0.5)$ & $4.1(0.6)$ & 0.8506 \\
\hline Hemoglobin(g/dl) & $12.6(2.0)$ & $12.3(1.8)$ & 0.6378 \\
\hline Hematocrit(\%) & $39.4(5.5)$ & $37.4(5.3)$ & 0.4703 \\
\hline Platelet(X1000/ml) & $304.1(121.2)$ & $285.9(108.4)$ & 0.7064 \\
\hline Albumin(g/dl) & $3.9(0.4)$ & $3.2(0.6)$ & 0.0052 \\
\hline Aspartate Aminotransferase(IU/I) & $32.6(39.8)$ & $38.6(27.2)$ & 0.1167 \\
\hline Alanine Aminotransferase(IU/I) & $28.0(36.3)$ & $26.4(28.8)$ & 0.8068 \\
\hline Lactate Dehydrogenase(IU/I) & $224.7(39.1)$ & $371.8(143.4)$ & 0.0052 \\
\hline Alkaline Phosphatase(IU/I) & $275.4(129.1)$ & $260.4(93.3)$ & 0.9721 \\
\hline Y-glutamyltransferase(IU/I) & $33.5(25.4)$ & $110.9(309.5)$ & 0.1361 \\
\hline Creatinine(mg/dl) & $0.6(0.1)$ & $0.7(0.2)$ & 0.3627 \\
\hline Blood Urea Nitrogen(mg/dl) & $14.2(2.8)$ & $17.3(4.6)$ & 0.1005 \\
\hline C-reactive protein(mg/dl) & $3.6(3.6)$ & $11.1(9.3)$ & 0.1094 \\
\hline KL-6(IU/ml) & $447.9(244.3)$ & $829.2(473.8)$ & 0.0052 \\
\hline Surfactant Protein-D (SP-D)(U/ml) & $74.1(51.1)$ & $169.3(148.0)$ & 0.0157 \\
\hline TIMP-1(pg/ml) & 196945 (49413) & $302152(102113)$ & 0.0071 \\
\hline TIMP-2(pg/ml) & 117585 (23704) & $99258(16673)$ & 0.0231 \\
\hline MMP-3(pg/ml) & $910356(732400)$ & 451701 (312564) & 0.0057 \\
\hline Osteopontin(pg/ml) & 17095 (13228) & $36200(35682)$ & 0.0198 \\
\hline Eotaxin2(pg/ml) & $4482(3387)$ & $3308(4017)$ & 0.0108 \\
\hline IL-1RA(pg/ml) & $187(365)$ & $401(359)$ & 0.0759 \\
\hline IL-2Ra(pg/ml) & $3842(2128)$ & $8624(6810)$ & 0.0025 \\
\hline IL-6(pg/ml) & $123(260)$ & $383(852)$ & 0.1119 \\
\hline MMP-1 (pg/ml) & 81755 (93582) & 87509 (60314) & 0.0582 \\
\hline MMP-8(pg/ml) & $28379(17114)$ & 55764 (59399) & 0.1841 \\
\hline MMP-3/MMP-1 & $20.66(20.57)$ & $12.83(20.91)$ & 0.0249 \\
\hline
\end{tabular}

RA: rheumatoid arthritis, AoDILD: Acute-onset diffuse interstitial lung disease. Average values of each group are shown. Standard deviations are shown in parenthesis. Differences were tested by Wilcoxon signed-rank test. 
Table 3 Laboratory findings and serum biomarker levels of collagen disease patients with AE-ILD or DI-ILD in stable and AoDILD states

\begin{tabular}{|c|c|c|c|c|c|c|}
\hline & \multicolumn{2}{|l|}{ AE-ILD $(n=9)$} & \multirow[b]{2}{*}{$P$} & \multicolumn{2}{|l|}{ DI-ILD (n= 14) } & \multirow[b]{2}{*}{$P$} \\
\hline & Stable & AoDILD & & Stable & AoDILD & \\
\hline White Blood Cell count (X1000/ml) & $10.9(2.7)$ & $11.8(2.6)$ & 0.2135 & $10.3(4.0)$ & $12.1(3.8)$ & 0.2604 \\
\hline Red Blood Cell count $\left(X 10^{6} / \mathrm{ml}\right)$ & $4.2(0.9)$ & $4.4(0.7)$ & 0.9528 & $4.2(0.5)$ & $4.1(0.6)$ & 0.5536 \\
\hline Hemoglobin (g/dl) & $13.4(1.2)$ & $12.7(2.5)$ & 0.2936 & $12.6(2.3)$ & $12.2(1.9)$ & 0.5147 \\
\hline Hematocrit (\%) & $42.1(3.1)$ & $38.9(6.4)$ & 0.0152 & $38.9(6.4)$ & $36.9(5.9)$ & 0.9528 \\
\hline Platelet (X1000/ml) & $280.3(58.0)$ & $299.5(110.0)$ & 0.3139 & $318.2(139.3)$ & $293.5(118.8)$ & 0.8590 \\
\hline Albumin (g/dl) & $4.1(0.3)$ & $3.6(0.7)$ & 0.0077 & $3.9(0.4)$ & $3.2(0.6)$ & 0.0687 \\
\hline Aspartate Aminotransferase (IU/I) & $41.2(47.9)$ & $44.4(32.4)$ & 0.6784 & $23.2(4.6)$ & $31.8(13.6)$ & 0.1282 \\
\hline Alanine Aminotransferase (IU/I) & $36.6(43.2)$ & $39.0(36.2)$ & 0.4838 & $19.7(6.8)$ & $18.0(6.0)$ & 0.6784 \\
\hline Lactate Dehydrogenase (IU/I) & $250.7(45.3)$ & $311.6(86.2)$ & 0.1386 & $215.2(23.8)$ & $383.6(158.3)$ & 0.0209 \\
\hline Alkaline Phosphatase (IU/I) & $278.1(141.2)$ & $239.3(97.9)$ & 0.7794 & $243.8(89.5)$ & $261.8(90.2)$ & 0.9528 \\
\hline Y-glutamyltransferase (IU/I) & $52.2(44.4)$ & $179.5(392.2)$ & 0.1551 & $26.3(18.0)$ & $31.1(14.9)$ & 0.4990 \\
\hline Creatinine (mg/dl) & $0.7(0.1)$ & $0.7(0.1)$ & 0.8127 & $0.6(0.1)$ & $0.7(0.2)$ & 0.8127 \\
\hline Blood Urea Nitrogen (mg/dl) & $13.9(2.3)$ & $17.1(6.2)$ & 0.1097 & $14.4(3.1)$ & $16.8(3.5)$ & 0.4008 \\
\hline C-reactive protein (mg/dl) & $2.1(2.3)$ & $6.4(10.1)$ & 0.1097 & $3.9(4.1)$ & $11.2(7.7)$ & 0.2135 \\
\hline $\mathrm{KL}-6(\mathrm{U} / \mathrm{ml})$ & $2078.1(2525.4)$ & $2105.8(2495.5)$ & 0.0280 & $431.0(256.6)$ & $799.7(425.9)$ & 0.0208 \\
\hline Surfactant Protein-D (ng/ml) & $160.7(126.5)$ & $194.7(123.2)$ & 0.1763 & $76.4(53.5)$ & $170.5(163.6)$ & 0.0619 \\
\hline TIMP-1 (pg/ml) & 192899 (54474) & 245030 (93165) & 0.3105 & $218303(58054)$ & 313999 (91931) & 0.0166 \\
\hline TIMP-2 (pg/ml) & 123534 (24219) & $100422(12693)$ & 0.1763 & 120044 (21985) & 102973 (21694) & 0.0125 \\
\hline TIMP-3 (pg/ml) & $16813(5411)$ & 18791 (9923) & 0.7353 & $14857(14822)$ & 13457 (5240) & 0.1097 \\
\hline MMP-3 (pg/ml) & $587882(245290)$ & 628244 (328962) & 0.5940 & 1025348 (787427) & 416640 (271619) & 0.0019 \\
\hline MMP-9 (pg/ml) & 2852316 (1698909) & 2800269 (1205613) & 0.5940 & 2463095 (1473636) & 2860985 (1837002) & 0.5509 \\
\hline Osteopontin (pg/ml) & 12464 (10678) & 28442 (35397) & 0.0663 & 15979 (13604) & 31356 (32402) & 0.0736 \\
\hline Eotaxin2 (pg/ml) & 3953 (2312) & $5311(5724)$ & 0.3139 & $4846(3566)$ & $3523(4453)$ & 0.0258 \\
\hline IL-1RA (pg/ml) & $94(111)$ & 417 (653) & 0.0796 & $196(409)$ & 390 (346) & 0.2209 \\
\hline IL-2Ra (pg/ml) & 2611 (1669) & 3689 (2047) & 0.0506 & 4274 (2147) & 9899 (7159) & 0.0076 \\
\hline IL-6 (pg/ml) & $37(47)$ & $238(422)$ & 0.0209 & $145(290)$ & 444 (952) & 0.2455 \\
\hline MMP-1 (pg/ml) & 26532 (18626) & 44551 (43273) & 0.1097 & 97389 (100090) & 95411 (58164) & 0.0962 \\
\hline MMP-8 (pg/ml) & 24640 (18134) & 49581 (74715) & 0.3743 & 26573 (17394) & 48134 (36641) & 0.1401 \\
\hline MMP-3/MMP-1 & 29.78 (16.71) & $29.11(24.88)$ & 0.7671 & 17.07 (17.98) & $5.92(4.81)$ & 0.0043 \\
\hline
\end{tabular}

AoDILD: Acute-onset diffuse interstitial lung disease, AE-ILD: acute exacerbation of interstitial lung disease, DI-ILD: drug-induced interstitial lung disease. Average values of each group are shown. Standard deviations are shown in parenthesis. Differences were tested by Wilcoxon signed-rank test.

patients. These biomarker profiles were similar to that of collagen disease patients with AoDILD.

\section{Serum biomarker profile of the patients with AE-ILD or DI-ILD}

We also explored biomarkers associated with AoDILD in the patients with AE-ILD or DI-ILD. Characteristics of the AE-ILD $(n=9)$ and DI-ILD patients $(n=14)$ are shown in Additional file 5: Table S4. The laboratory findings of the patients with AE-ILD or DI-ILD in the stable state and in the AoDILD state are shown in Table 3. KL-6 was increased in AoDILD of patients with AE-ILD. Albumin and hematocrit were decreased in
AoDILD of patients with AE-ILD. KL-6 and lactate dehydrogenase were increased in AoDILD of patients with DI-ILD.

The serum IL-6 level was significantly increased in patients with AE-ILD in the AoDILD state (Table 3, Figure 1B). While the serum TIMP-1 and IL-2R levels were significantly increased in patients with DI-ILD in the AoDILD state (Table 3, Figure 1B), TIMP-2, MMP-3, and eotaxin 2 were decreased. The ratio of MMP-3 to MMP-1 was also reduced in the AoDILD state in these patients. These skewed biomarker profiles suggest differences in the pathogenesis of AoDILD in patients with AE-ILD or DI-ILD. 
Table 4 Laboratory findings and serum biomarker levels of collagen disease patients with different clinical outcome in stable and AoDILD states

\begin{tabular}{|c|c|c|c|c|c|c|}
\hline & \multicolumn{3}{|l|}{ Died $(n=9)$} & \multicolumn{3}{|l|}{ Survived $(n=14)$} \\
\hline & Stable & AoDILD & $P$ & Stable & AoDILD & $P$ \\
\hline White Blood Cell count(X1000/ml) & $8.5(1.7)$ & $10.4(1.8)$ & 0.138 & $11.4(3.6)$ & $13.0(3.7)$ & 0.279 \\
\hline Red Blood Cell count(X106/ml) & $4.3(0.3)$ & $3.9(0.7)$ & 0.043 & $4.1(0.8)$ & $4.4(0.6)$ & 0.069 \\
\hline Hemoglobin(g/dl) & $13.7(1.2)$ & $11.7(2.7)$ & 0.043 & $12.7(2.0)$ & $12.9(1.7)$ & 0.108 \\
\hline Hematocrit(\%) & $41.5(3.5)$ & $35.6(6.7)$ & 0.043 & $40.1(5.8)$ & $39.2(5.4)$ & 0.917 \\
\hline Platelet(X1000/ml) & $266.0(62.5)$ & $310.1(131.2)$ & 0.281 & $312.1(119.0)$ & $287.1(102.4)$ & 0.972 \\
\hline Albumin(g/dl) & $3.9(0.2)$ & $3.0(0.6)$ & 0.068 & $4.1(0.5)$ & $3.6(0.5)$ & 0.005 \\
\hline Aspartate Aminotransferase(IU/I) & $54.2(60.6)$ & $43.3(34.2)$ & 0.893 & $23.8(6.8)$ & $33.5(14.0)$ & 0.068 \\
\hline Alanine Aminotransferase(IU/I) & $47.0(55.2)$ & $34.1(38.9)$ & 0.500 & $20.8(7.8)$ & $22.6(11.1)$ & 0.480 \\
\hline Lactate Dehydrogenase(IU/I) & $234.0(32.2)$ & $361.8(92.8)$ & 0.138 & $232.5(43.0)$ & $346.2(158.2)$ & 0.039 \\
\hline Alkaline Phosphatase(IU/I) & $320.2(169.8)$ & $224.9(67.2)$ & 0.144 & $238.2(82.4)$ & $268.5(103.1)$ & 0.221 \\
\hline Y-glutamyltransferase(IU/I) & $42.4(32.7)$ & $179.1(413.2)$ & 0.419 & $38.1(37.5)$ & $42.8(44.2)$ & 0.142 \\
\hline Creatinine(mg/dl) & $0.7(0.1)$ & $0.7(0.2)$ & 0.419 & $0.7(0.1)$ & $0.7(0.1)$ & 0.422 \\
\hline Blood Urea Nitrogen $(\mathrm{mg} / \mathrm{dl})$ & $13.1(2.5)$ & $15.1(5.2)$ & 0.715 & $14.5(2.7)$ & $18.1(4.3)$ & 0.039 \\
\hline C-reactive protein(mg/dl) & $0.8(0.5)$ & $12.0(8.6)$ & 0.080 & $3.8(3.7)$ & $7.3(9.0)$ & 0.311 \\
\hline $\mathrm{KL}-6(\mathrm{U} / \mathrm{ml})$ & $1364.1(2423.4)$ & $1565.4(2498.4)$ & 0.025 & $837.5(936.0)$ & $1173.8(898.0)$ & 0.017 \\
\hline Surfactant Protein-D(ng/ml) & $136.8(125.6)$ & $196.0(114.4)$ & 0.036 & $87.1(60.4)$ & $169.6(167.8)$ & 0.203 \\
\hline TIMP-1 (pg/ml) & 231906 (68528) & $346576(72337)$ & 0.080 & $197816(49624)$ & 260193 (96764) & 0.084 \\
\hline TIMP-2(pg/ml) & $118406(27648)$ & $105669(20160)$ & 0.345 & $122762(20616)$ & 100361 (17629) & 0.012 \\
\hline TIMP-3(pg/ml) & 10668 (6632) & 15759 (12498) & 0.043 & $17743(12977)$ & 15609 (4998) & 0.790 \\
\hline MMP-3(pg/ml) & 752633 (495718) & $513110(247738)$ & 0.214 & 919436 (751496) & 490655 (348157) & 0.030 \\
\hline MMP-9(pg/ml) & 1769108 (1012232) & 3358493 (1977141) & 0.011 & 3159443 (1634403) & 2502127 (1229009) & 0.140 \\
\hline Osteopontin(pg/ml) & 13588 (9212) & $51660(44658)$ & 0.008 & $15256(14407)$ & $16430(9537)$ & 0.551 \\
\hline Eotaxin 2(pg/ml) & $4854(4321)$ & $4320(5943)$ & 0.110 & 4267 (2079) & $4160(4408)$ & 0.096 \\
\hline IL-1RA(pg/ml) & $224(463)$ & $657(559)$ & 0.086 & $112(190)$ & $236(352)$ & 0.445 \\
\hline IL-2Ra(pg/ml) & 3827 (2213) & $8408(4328)$ & 0.011 & 3492 (2072) & $6865(7488)$ & 0.064 \\
\hline IL-6(pg/ml) & $156(339)$ & $710(1157)$ & 0.066 & $69(115)$ & $140(222)$ & 0.328 \\
\hline MMP-1(pg/ml) & 35772 (19709) & 73909 (39388) & 0.011 & 91449 (103647) & 76538 (67816) & 0.397 \\
\hline MMP-8 (pg/ml) & $14814(12583)$ & $51014(40613)$ & 0.008 & $32889(16905)$ & $47213(62177)$ & 0.826 \\
\hline MMP-3/MMP-1 & $23.67(18.54)$ & $10.29(8.39)$ & 0.028 & $21.00(18.50)$ & $18.02(23.73)$ & 0.221 \\
\hline
\end{tabular}

AoDILD: Acute-onset diffuse interstitial lung disease. Average values of each group are shown. Standard deviations are shown in parenthesis. Differences were tested by Wilcoxon signed-rank test.

\section{Association of serum biomarker profile with outcome}

The characteristics of 23 collagen disease patients with AoDILD are shown in Additional file 6: Table S5. There were no significant differences between those who died and those who survived. KL-6 and SP-D were increased and red blood cell count, hemoglobin, and hematocrit were decreased in the AoDILD state of patients who died $(n=9$, Table 4$)$. Lactate dehydrogenase, blood urea nitrogen and KL-6 were increased and albumin decreased in the AoDILD state in patients who survived $(\mathrm{n}=14)$. TIMP-3, MMP-9, osteopontin, IL$2 \mathrm{R} \alpha$, MMP-1, and MMP-8 levels were significantly increased in the AoDILD state in the deceased patients.
The ratio of MMP-3 to MMP-1 was decreased in the AoDILD state in the deceased patients (Table 4, Figure $1 \mathrm{C}$ ). On the other hand, the serum TIMP2 and MMP-3 levels were decreased in the AoDILD state in patients who survived. Thus, biomarker profiles were different in patients with different outcomes.

\section{Discussion}

Many studies have reported on biomarker profiles in IPF or ARDS patients [4-6]. The roles of MMPs and TIMPs in IPF or ARDS have been reported [10-12]. Involvement of other biomarkers in IPF or ARDS, including osteopontin [13], eotaxin 2 (CCL24) [14], IL-1RA [15,16], IL- 2R $\alpha$ [17], 
and IL-6 [18], were also inferred. The present study reports novel biomarker profiles of AoDILD occurring in collagen disease patients, though a few of these biomarkers have been analyzed previously in such patients with chronic CVD-ILD [20,21]. Administration of the cytokines found to be decreased, or blocking cytokines found to be increased with antibodies or inhibitors could represent new therapeutic approaches for AoDILD in collagen disease patients [22].

We also propose that serum biomarker patterns could represent prognostic markers for AoDILD in collagen diseases. Several studies reported that the expression of MMP-1 and MMP-3 by fibroblasts and chondrocytes was correlated $[12,23]$. This was measured as the ratio of MMP-3 to MMP-1 and was maintained in the sera of patients who survived, but not in those who died (Table 4, Figure 1C). Similarly, different biomarker profiles were seen in deceased and surviving patients. These biomarkers were up-regulated in the sera of the patients with AoDILD who died (TIMP-3, MMP-9, osteopontin, IL2R $\alpha$, MMP-1, and MMP-8, Figure 1C) or down-regulated in the sera of the patients with AoDILD who survived (TIMP2 and MMP-3). These biomarker molecules might accelerate the progress of AoDILD and could be targets blocked with antibodies or inhibitors for the treatment. Since there were no oppositely regulated biomarker molecules, we could not find any molecules that might prevent the progress of AoDILD. Role of other molecules in the pathological state of AoDILD, such as TIMP-1, eotaxin 2, IL-1RA, or IL-6 could not be estimated in this study. Thus, the MMP-3 to MMP-1 ratio, and levels of TIMP-3, MMP9, and osteopontin could be prognostic markers for AoDILD in collagen diseases.

The serum osteopontin $(P=0.0233$, Mann-Whitney $\mathrm{U}$ test), IL-1RA $(P=0.0350)$, and IL-6 $(P=0.0320)$ levels were higher in patients who died in the AoDILD state, compared with those who survived (Table 4). The serum MMP-9 $(P=0.0376$, Mann-Whitney $U$ test $)$ and MMP-8 $(P=0.0167)$ levels were higher in patients who survived in the stable state, compared with those who died (Table 4). These data suggest that some biomarkers could represent prognosis of the patients with AoDILD, without comparison of the paired serum levels between stable and AoDILD states.

The ratio of MMP-3 to MMP-1 was maintained in the sera of AE-ILD patients (Table 3, Figure 1B). However, the correlation was no longer present in DI-ILD patients (Table 3). In addition, serum profiles of eotaxin 2 and MMP-3 were completely different in patients with AE-ILD and DI-ILD. The serum IL$2 \mathrm{R} \alpha,(P=0.0406$, Mann-Whitney $\mathrm{U}$ test $)$ and MMP-1 $(P=0.0140)$ levels were higher in patients with DI-ILD in the AoDILD state, compared with those with AE-ILD (Table 3). The ratio of MMP-3 to MMP-1 was lower in patients with DI-ILD in the AoDILD state, compared with those with AE-ILD $(P=0.0068$, Table 3$)$. The serum MMP-1 ( $P=0.0016$, Mann-Whitney $U$ test $)$ level was higher in patients with DI-ILD in the stable state, compared with those with AE-ILD (Table 3). Thus, our findings suggest the possibility of different pathogenesis of AE-ILD and DI-ILD. Because of the limited sample size of this study, the expression pattern of these biomarkers needs to be confirmed in future studies.

\section{Conclusions}

To our knowledge, this is the first report of biomarker profiling in AoDILD occurring in collagen disease patients. Our findings support the role of serum biomarker profiles as prognosis markers for AoDILD.

\section{Additional files}

Additional file 1: Table S1. Laboratory findings of collagen disease patients in the stable and the AoDILD state.

Additional file 2: Table S2. Cytokine expression ratios in sera of the patients between stable and AoDILD states.

Additional file 3: Figure S1. Biomarker levels in individual serum without pooling from collagen disease patients in the stable and AoDILD states.

Additional file 4: Table S3. Characteristics of collagen disease or RA patients with AoDILD.

Additional file 5: Table S4. Characteristics of collagen disease patients with AE-ILD or DI-ILD.

Additional file 6: Table S5. Characteristics of collagen disease patients with AoDILD with different clinical outcome.

\section{Abbreviations}

AE-ILD: Acute exacerbation of ILD; AoDILD: Acute-onset diffuse ILD; ARDS: Acute respiratory distress syndrome; CVD-ILD: Collagen vascular disease-associated ILD; DI-ILD: Drug-induced ILD; EGF: Epidermal growth factor; FasL: Fas ligand; IL: Interleukin; IL-1RA: IL-1 receptor antagonist; IL-2Ra: Interleukin-2 receptor a; ILD: Interstitial lung disease; IPF: Idiopathic pulmonary fibrosis; LIF: Leukaemia inhibitory factor; MIF: Migration inhibitory factor; MMP: Matrix metalloproteinase; PM/DM: Polymyositis/ dermatomyositis; RA: Rheumatoid arthritis; SD: Standard deviation; SP-D: Surfactant protein-D; SSC: Systemic sclerosis; TGF: Transforming growth factor; TIMP: Tissue inhibitor of metalloproteinase; TNF: Tumor necrosis factor.

\section{Competing interests}

HF has the following conflicts. The following funders are supported in whole or in part by the subsequent pharmaceutical companies. The Japan Research Foundation for Clinical Pharmacology is run by Daiichi Sankyo, the Takeda Science Foundation is supported by an endowment from Takeda Pharmaceutical Company and the Nakatomi Foundation was established by Hisamitsu Pharmaceutical Co., Inc. The Daiwa Securities Health Foundation was established by Daiwa Securities Group Inc. ST was supported by research grants from pharmaceutical companies: Abbott Japan Co., Ltd., Astellas Pharma Inc., AstraZeneca K.K., Bristol-Myers Squibb Co Ltd., Chugai Pharmaceutical Co., Ltd., Eisai Co., Ltd., Medical \& Biological Laboratories Co., Ltd, Mitsubishi Tanabe Pharma Corporation, Merck Sharp and Dohme Inc., Pfizer Japan Inc., Takeda Pharmaceutical Company Limited, and Teijin Pharma Limited. The other authors declare no financial or commercial conflict of interest.

\section{Authors' contributions}

SO and HF carried out immunoassay, participated in the design of the study, performed the statistical analysis, and wrote the manuscript. KS, HF, and ST 
recruited Japanese patients with collagen diseases and collected clinical information. $\mathrm{HH}$ collected serum samples. NF, NT, and ST conceived the study, participated in its design and coordinated and helped to draft the manuscript. All authors read and approved the final manuscript.

\section{Acknowledgements}

We thank Ms. Mayumi Yokoyama (Sagamihara Hospital) for secretarial assistance. The work was supported by Grants-in-Aid for Scientific Research from the Japan Society for the Promotion of Science, Health and Labour Science Research Grants from the Ministry of Health, Labour, and Welfare of Japan, Grants-in-Aid for Clinical Research from National Hospital Organization, Research Grants from Japan Research Foundation for Clinical Pharmacology, Research Grants from Takeda Science Foundation, Research Grants from Daiwa Securities Health Foundation, and Research Grants from The Nakatomi Foundation.

\section{Author details}

${ }^{1}$ Clinical Research Center for Allergy and Rheumatology, Sagamihara Hospital, National Hospital Organization, 18-1 Sakuradai, Minami-ku, Sagamihara, Kanagawa 252-0392, Japan. ²Department of Rheumatology, Sagamihara Hospital, National Hospital Organization, 18-1 Sakuradai, Minami-ku, Sagamihara 252-0392, Japan. ${ }^{3}$ Tokyo Metropolitan Tama Medical Center, 2-8-29 Musashi-dai, Fuchu 183-8524, Japan. ${ }^{4}$ Molecular and Genetic Epidemiology Laboratory, Faculty of Medicine, University of Tsukuba, 1-1-1 Tennodai, Tsukuba 305-8575, Japan.

Received: 30 October 2012 Accepted: 1 February 2013 Published: 14 February 2013

\section{References}

1. Turesson C, Jacobsson LT: Epidemiology of extra-articular manifestations in rheumatoid arthritis. Scand J Rheumatol 2004, 33:65-72.

2. Koduri G, Norton S, Young A, Cox N, Davies P, Devlin J, Dixey J, Gough A, Prouse $P$, Winfield J, et al: Interstitial lung disease has a poor prognosis in rheumatoid arthritis: results from an inception cohort. Rheumatology 2010, 49:1483-1489.

3. Kameda H, Tokuda H, Sakai F, Johkoh T, Mori S, Yoshida Y, Takayanagi N, Taki $H$, Hasegawa $Y$, Hatta $K$, et al: Clinical and radiological features of acute-onset diffuse interstitial lung diseases in patients with rheumatoid arthritis receiving treatment with biological agents: importance of Pneumocystis pneumonia in Japan revealed by a multicenter study. Intern Med 2011, 50:305-313.

4. Ricou B, Nicod L, Lacraz S, Welgus HG, Suter PM, Dayer JM: Matrix metalloproteinases and TIMP in acute respiratory distress syndrome. Am J Respir Crit Care Med 1996, 154:346-352.

5. Suga M, lyonaga K, Okamoto T, Gushima Y, Miyakawa H, Akaike T, Ando M: Characteristic elevation of matrix metalloproteinase activity in idiopathic interstitial pneumonias. Am J Respir Crit Care Med 2000, 162:1949-1956.

6. Ohbayashi H: Matrix metalloproteinases in lung diseases. Curr Protein Pept Sci 2002, 3:409-421.

7. Arnett FC, Edworthy SM, Bloch DA, McShane DJ, Fries JF, Cooper NS, Healey LA, Kaplan SR, Liang MH, Luthra HS, et al: The American Rheumatism Association 1987 revised criteria for the classification of rheumatoid arthritis. Arthritis Rheum 1988, 31:315-324

8. Subcommittee for Scleroderma Criteria of the American Rheumatism Association Diagnostic and Therapeutic Criteria Committee: Preliminary criteria for the classification of systemic sclerosis (scleroderma). Arthritis Rheum 1980, 23:581-590.

9. Bohan A, Peter JB: Polymyositis and dermatomyositis (first of two parts). N Engl J Med 1975, 292:344-347.

10. Selman M, Ruiz V, Cabrera S, Segura L, Ramirez R, Barrios R, Pardo A: TIMP-1, $-2,-3$, and -4 in idiopathic pulmonary fibrosis. A prevailing nondegradative lung microenvironment? Am J Physiol Lung Cell Mol Physiol 2000, 279:L562-L574.

11. Rosas IO, Richards TJ, Konishi K, Zhang Y, Gibson K, Lokshin AE, Lindell KO, Cisneros J, Macdonald SD, Pardo A, et al: MMP1 and MMP7 as potential peripheral blood biomarkers in idiopathic pulmonary fibrosis. PLOS Med 2008, 5:e93.

12. Fligiel SE, Standiford T, Fligiel HM, Tashkin D, Strieter RM, Warner RL Johnson KJ, Varani J: Matrix metalloproteinases and matrix metalloproteinase inhibitors in acute lung injury. Hum Pathol 2006, 37:422-430.

13. Pardo A, Gibson K, Cisneros J, Richards TJ, Yang Y, Becerril C, Yousem S, Herrera I, Ruiz V, Selman M, et al: Up-regulation and profibrotic role of osteopontin in human idiopathic pulmonary fibrosis. PLoS Med 2005, 2:e251.

14. Kohan M, Puxeddu I, Reich R, Levi-Schaffer F, Berkman N: Eotaxin-2/CCL24 and eotaxin-3/CCL26 exert differential profibrogenic effects on human lung fibroblasts. Ann Allergy Asthma Immunol 2010, 104:66-72.

15. Smith DR, Kunkel SL, Standiford TJ, Rolfe MW, Lynch JP 3rd, Arenberg DA, Wilke CA, Burdick MD, Martinez FJ, Hampton JN, et al: Increased interleukin-1 receptor antagonist in idiopathic pulmonary fibrosis. A compartmental analysis. Am J Respir Crit Care Med 1995, 151:1965-1973.

16. Vasakova M, Sterclova M, Kolesar L, Slavcev A, Pohunek P, Sulc J, Skibova J, Striz I: Bronchoalveolar lavage fluid cellular characteristics, functional parameters and cytokine and chemokine levels in interstitial lung diseases. Scand J Immunol 2009, 69:268-274.

17. Homolka J, Ziegenhagen MW, Gaede Kl, Entzian P, Zissel G, MullerQuernheim J: Systemic immune cell activation in a subgroup of patients with idiopathic pulmonary fibrosis. Respiration 2003, 70:262-269.

18. Collard HR, Calfee CS, Wolters PJ, Song JW, Hong SB, Brady S, Ishizaka A, Jones KD, King TE Jr, Matthay MA, et al: Plasma biomarker profiles in acute exacerbation of idiopathic pulmonary fibrosis. Am J Physiol Lung Cell Mol Physiol 2010, 299:L3-L7.

19. Lewicki M, Kotyla P, Kucharz E: Increased adiponectin levels in women with rheumatoid arthritis after etanercept treatment. J Rheumatol 2009, 36:1346-1347.

20. Andersen GN, Nilsson K, Pourazar J, Hackett TL, Kazzam E, Blomberg A Waldenstrom A, Warner J, Rantapaa-Dahlqvist S, Mincheva-Nilsson L, et al: Bronchoalveolar matrix metalloproteinase 9 relates to restrictive lung function impairment in systemic sclerosis. Respir Med 2007, 101:2199-2206.

21. Manetti M, Guiducci S, Romano E, Bellando-Randone S, Conforti ML, IbbaManneschi L, Matucci-Cerinic M: Increased serum levels and tissue expression of matrix metalloproteinase-12 in patients with systemic sclerosis: correlation with severity of skin and pulmonary fibrosis and vascular damage. Ann Rheum Dis 2012, 71:1064-1072.

22. Oikonomidi S, Kostikas K, Tsilioni I, Tanou K, Gourgoulianis Kl, Kiropoulos TS Matrix metalloproteinases in respiratory diseases: from pathogenesis to potential clinical implications. Curr Med Chem 2009, 16:1214-1228.

23. Ahn JK, Koh EM, Cha HS, Lee YS, Kim J, Bae EK, Ahn KS: Role of hypoxiainducible factor-1alpha in hypoxia-induced expressions of IL-8, MMP-1 and MMP-3 in rheumatoid fibroblast-like synoviocytes. Rheumatology (Oxford) 2008, 47:834-839.

doi:10.1186/1471-2172-14-9

Cite this article as: Oka et al:: Serum biomarker analysis of collagen disease patients with acute-onset diffuse interstitial lung disease. BMC Immunology 2013 14:9.

\section{Submit your next manuscript to BioMed Central and take full advantage of:}

- Convenient online submission

- Thorough peer review

- No space constraints or color figure charges

- Immediate publication on acceptance

- Inclusion in PubMed, CAS, Scopus and Google Scholar

- Research which is freely available for redistribution 